\title{
User-centred Design and Evaluation of Web and Mobile based Travelling Applications
}

\author{
Nor Azman Ismail, Siti Fatimah Nizam, Simon Yuen, Layla Hasan \\ Su Elya Mohamed, Wong Yee Leng, Khalid Krayz Allah \\ School of Computing, Faculty of Engineering \\ Universiti Teknologi Malaysia \\ Johor, Malaysia
}

\begin{abstract}
Travelling has been known as one of the top-rated activities people do during their leisure time. In this digital time, people usually research before visiting a new place to avoid unpleasant events and to have a well-planned trip. Due to the complexity of search engine browsers, people have been switching to designated travelling applications. Travelling applications should be designed by taking into consideration user's needs and requirements; and usability. This research aims to design a travelling application based on a user-centred design approach and compare its performance on different platforms. Two prototypes of travelling applications were designed and evaluated; web-based and mobile-based. Then, System Usability Scale (SUS) questionnaire was used to evaluate the usability of the two prototypes. Pearson correlation coefficient test and t-test were used to analyses the data collected from the questionnaire. The results showed no statistically significant difference in SUS scores for both prototypes, which indicates that the participants do not prefer any of the prototypes more than another one.
\end{abstract}

Keywords-Usability; travelling application; SUS questionnaire: low-fidelity prototype; user-centred design (UCD)

\section{INTRODUCTION}

Recent development of information and communication technologies has played a central role in the growth and improvement of the travel and tourism industry $[1,2,3]$. Numerous travel and tourism practitioners attempt to understand the effects of IT applications in managing and distributing travel products and services [4]. Interesting information about travel destinations and other required services (such as accommodations, restaurants) is commonly searched via the Internet by tourists to plan a trip [2]. However, the results obtained by the search engines may be overwhelming, complex and time consuming for tourists. A few problems have been determined using search engines, such as poor queries, language barriers, and inefficiency due to the abundance of resources available on the web of the new places. Many people do not know how to express what they want in the real world and are even worse when using a search engine [5].

Moreover, search engines consider language factors when ranking results. Results in languages different from the language the user uses give a lower ranking [6]. The results from the search engine also sometimes are not related to the one that users tend to search. Hence, people have been switching to designated travelling applications to ease themselves in finding related information efficiently. Travel applications offer various functionalities for tourists, such as hotel booking, car renting, and flight booking [7]. These applications are considered the most downloaded applications around the globe [8].

In the competitive travel and tourism industry, usercentered design and usability are key factors for successful travel websites [7, 9-14]. Usability is a quality attribute that evaluates how easy user interfaces are to use, and it is a necessary condition for survival $[15,16]$. If a travel application is difficult to use, people will leave to other competitor applications [7].

Research investigating user behavior to a travel application found that travelers have a positive attitude towards the application and produce positive usage intention, leading to the future formulation of new travel application policies and strategies [17]. In the study of travel application attributes and features, Fang et al. [18] proposed a research framework based on the Stimulus-Organism-Responses model to explore how the application attributes and characteristics could stimulate travel application engagement. The results reveal that user interface attractiveness, privacy, compatibility and ease of use are important drivers of users' behavioral engagement of travel applications.

Although various tour travel applications were developed to guide tourist activities [19-23], there is a lack of research that designs a travel application considering users' requirements and needs and usability. This gap motivated this research which concerned designing a usable travel application based on users' requirements and needs. Considering user's requirements and needs is important when designing and developing applications to ensure that the application will be accepted [24, 25]. Other advantages of designing usable travel applications include: increasing the success and profits of the travel applications; contributing to the growth of the economy by increasing revenues generated from tourism [11]; and improving users' experience and interaction.

This research aims to design and evaluate a web-based and mobile travel application based on users' needs and requirements. The specific objectives of the study are:

1) To collect users' requirements and needs regarding travel applications; 
2) Based on Objective 1, to analyses the results and to design two prototypes: web-based and mobile;

3) To use the System Usability Scale (SUS) questionnaire to evaluate the usability of the two designed prototypes.

The results of this research would offer advice to travel application managers and designers on how to design usable travel applications by considering usability issues and users' requirements and needs which will be identified in this research.

\section{RELATED WORK}

\section{A. Usability of Travel Websites}

Various studies were found in the literature concerning the usability of travel websites. These studies can be divided into two categories: studies that employed various methods to evaluate travel websites' usability and other studies that suggested heuristics or guidelines to design or evaluate the usability of travel websites. The first category shed light on common usability problems on travel websites that can be considered and when designing travel websites. The second category, which suggested heuristics to evaluate the usability of travel websites, can also help develop travel websites by considering the identified criteria in the design and development of the new travel websites.

For example, Carstens \& Patterson [26] employed a user testing method to evaluate the usability of three common travel websites: Expedia.com, Orbitz.com, and Travelocity.com. The usability problems identified on the tested travel websites include: not easy to interact with the websites; inappropriate use of background and text colours; cluttered pages; compatibility; unavailability of in-depth search capabilities. Also, Ismail et al. [23] conducted a user testing method to evaluate the usability of four tourism websites in Malaysia and identified usability problems on these websites. The usability problems related to inconvenient data; outdated content; the user interface is displayed only in the English language; crowded content; require information from other websites; and slow loading of pages.

Furthermore, Bainbridge [7] conducted user testing methods to evaluate the usability of 87 hotel booking websites, including 16 travel agencies, 43 hotel booking agencies and 28 hotel chains. Examples of the usability problems identified specifically on the travel agencies include lack of displaying how the rate is calculated; long booking process; not handling multiple occupancies and multiple rate reservations, and not taking children's reservations. Based on the results obtained from the analysis of the usability problems, Bainbridge [7] suggested 25 key design characteristics (usability guidelines), which addressed the identified usability problems. The categories of the booking process design guidelines are the overall structure of the booking process, multi-room check-out, children, and displaying rate values.

Alternatively, Limayem et al. [27] employed a heuristic evaluation method to evaluate eighty travel agency websites in Hong Kong. The results showed that the interfaces of these websites were poorly designed and did not adhere to the wellknown design guidelines in terms of ease of navigation and consistency. The usability problems which were found on the travel websites include: lack of providing special features (such as last minutes discounts); inappropriate content (such as content was not updated, presenting confusing, unclear and vague information); the content was displayed only in the Chinese Language; lack of proving value-added services; lack of providing clear privacy statements.

However, Karanasios et al. [28] suggested a specific framework for designing or evaluating mobile tourism applications, consisting of four dimensions, ten features, and ten corresponding criteria. The dimensions are related to Service delivery, customization, and initiation and application type. Hashim and Isse [24] also proposed thirty-five usability evaluation metrics for tourism mobile applications, which can be used to design usable mobile applications for tourists. The metrics related to five usability dimensions, namely: Effectiveness, efficiency, learnability, satisfaction and error. The suggested metrics were verified and agreed by five experts to be accurate and applicable for tourism mobile applications usability evaluation.

\section{B. Travel Application for Guiding Tourist Activities}

Mobile travel applications were classified into four main categories [2]:

- Online Booking: these applications allow users to make online reservations for various services such as car rental, hotel, and airplane tickets.

- Information Resource: these applications provide the user with useful information during the trip, such as tourist destinations, flight tracking, the airport and accessible services.

- Location-Based Services: these applications provide the user context-based information based on their location, such as map and navigation services, police phones, and hospitals.

- Trip Journals: these applications allow the user to accumulate and analyses information related to the trip, such as: calculate the money spent for the journey.

- Setten et al. [19] described a context-aware mobile tourist application COMPASS, which provides context-aware recommendations based on both the user's interests and his current context. COMPASS is built upon the WASP platform, which provides generic supporting services with semantic web technology [2].

- Smirnov et al. [2] proposed a "Tourist assistant TAIS” mobile travel application related to Information Resources and Location-Based Services categories and recommended tourist attractions. TAIS applications generate recommendations for the tourist about interesting attractions around. TAIS response time was tested regarding the response time, and it was found that it will not take more than few seconds for every operation.

- Anacleto et al. [20] presented PSiS (Personalized Sightseeing Planning System), a mobile tour planning support system. It is designed to support tourists during 
their vacations by providing recommendations to the user based on their preferences. PSiS also suggest a visit planning that can be dynamically adapted based on the current user and sight context. The user can use PSiS via the special web application or the special mobile application for Android-based smartphones.

- Kramer et al. [21] described the development and evaluation of Dynamic Tour Guide (DTG), a mobile tourist guide. DTG supports the user based on the actual context, defined by personal interests, location and schedule. It enables a personalized, automatic and guided tour just like expert guidance. It computes an individual tour in real-time by considering available context information like personal interests and location-based services. It captures the user's interest profile and use it to rank and select concrete attractions in a destination to compute a personalized tour.

- Cheverst et al. [22] presented the development of GUIDE, a context-aware electronic tourist guide designed to guide tourists in the city of Lancaster, the UK. GUIDE suggested a tailored tour to the user based on their profile, contextual information and physical location. The user can change the tour. GUIDE also provides various booking facilities to the user.

- Ismail et al. [23] described the process of developing the iTourism Travel Buddy Mobile Application, which is a travel mobile application that was developed to support tourists in finding interesting places and related services in Malaysia. iTourism provides users with sufficient information regarding places to visit supported by actual images. It also offers tourist a secured journey since it can reconfirm the information and the places while matching it with the data from GPS.

\section{RESEARCH METHOD}

As shown in Fig. 1, this study is conducted in three phases: user requirement study and analysis, designing and developing a prototype, and usability testing and evaluation.
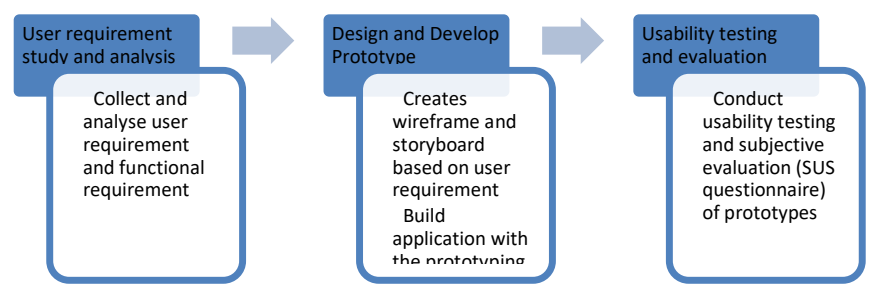

Fig. 1. Three main Phases of the Methodology.

\section{A. User Requirement Study and Analysis}

This phase mainly collected the users' opinions, thoughts, ideas, and feelings about planning a trip, and the feature or platform of the needs to plan a trip effectively. The user requirement study via questionnaire-based was conducted as the data gathering method. The questions are based on: earlier research which developed travel applications for guiding tourist activities, presented in Section 2.2, and usability guidelines which should be considered while developing travel applications, presented in Section 2.1. The questionnaire consisted of 22 questions, where these questions collected participants' personal information such as an e-mail address and their nationality. User requirement data were collected to study the participants' behavior, such as their thoughts, travel style, experience, a problem user's face while planning a trip, and their expectations of the new system in terms of feature, convenience, flexibility, and functionality. The survey questions were formed into two types: the user requirement used a qualitative method, and the functional requirement used a quantitative approach. The answered questions were based on their own opinions and experiences, followed by their expectations of the new coming system built with the proposed solutions. The questionnaires were given to 50 potential participants. The Results and Discussions Section presents the analysis of the user requirement.

\section{B. Design and Develop Prototype}

The storyboard was created to illustrate functional application requirements. Storyboards help establish a hierarchy for elements within a page, clearly define the grid and structure of the site, and help communicate to the team what the final piece should look like [29]. Next, a wireframe was created from the storyboard and then developed the prototypes using a prototyping tool (e.g., Figma).

\section{Usability Testing and Evaluation}

After the prototypes were designed, usability testing was conducted to evaluate the prototypes' usability and identify usability problems [30, 31]. User performance analysis with usability testing was conducted and collected information of subjective satisfaction using the SUS questionnaire. Fig. 2 shows the methodology of usability testing and evaluation that was used.

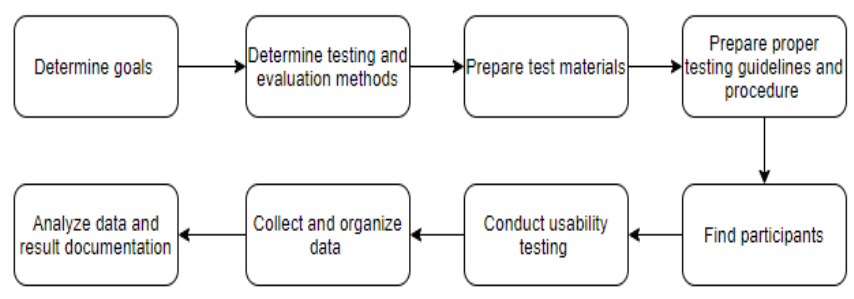

Fig. 2. The Methodology of Usability Testing and Evaluation.

1) Determine goals and testing methods: The primary purpose of this phase is to conduct a usability evaluation of the two prototypes to identify which prototype is preferred by the user. User performance analysis was chosen to collect subjective satisfaction using the System Usability Scale (SUS) questionnaire [32, 33].

2) Preparing test material: The test material was divided into three parts:

a) Prototype: In the previous phase, two interactive prototypes were designed using the Figma prototyping tool. This type of prototype allows to test design concepts and get feedback on the flow or functionality of a design [34]. One of the prototypes is a web-based prototype, while the other is a mobile phone prototype. In this study, prototypes are called 
modules. The web-based prototype is module 1 , and the mobile app prototype is module 2 .

b) Task: To test the user performance of both prototype versions, the participant was allowed to use and interact with the prototypes. It is crucial to ensure that the tasks are appropriately made based on user requirements and functional requirements gathered from the first phase.

c) Post-test questionnaire: This questionnaire is given after the participants have completed all given tasks scenario for each prototype. The primary purpose of the post-test questionnaire is to collect preference information from the participants to identify the application strengths and weaknesses. The System Usability Scale (SUS) questionnaire has used 10 Likert-scale questions and produced a score from 0-100 [32, 33].

3) Participants: Ten (10) participants were selected based on a purposive sampling method [35-37]. Moreover, it allows researchers to extract helpful information from the collected data, which is extremely time and cost-effective.

4) Conducting the test: Participants must follow the given procedure and guidelines and need to record their screen while completing the tasks. The video recording(s) was shared after completing the tasks for analyzing and evaluating. This method allows us to gather qualitative data of the test, such as capturing what participants did to complete the tasks [32]. The post-test questionnaire given to the participants was used to collect the subjective satisfaction from participants. The data collected from this questionnaire is the metric used to determine the usability of the prototypes.
5) Data analysis: From the recorded video, participants' task time to complete the test was calculated for each prototype. The formula is as follows:

\section{Task Time = End Time - Start Time}

From the task time of both modules, the Pearson $\mathrm{R}$ coefficient test was conducted to determine the correlation between modules 1 and 2. Next, the SUS questionnaire scores were calculated, and this data's mean and standard deviation was found. Finally, t-test analyses were performed.

\section{RESULTS AND DISCUSSION}

\section{A. User Requirement and Analysis}

Thirty-six (36) participants responded and shared their own opinions and comments on the questions about travelling activities used in the study. Most participants were primarily dependent on the internet search engine in their travel planning. Most participants think search engine browsers still provide them with the relevant answer, but most of them also agreed that it is difficult to find eateries and hot spots of a new place. We discovered that most of the participants are hesitant to hire a freelance tour guide. We also found that in this new era and new lifestyle, people nowadays are willing to accept the concept of "online", which greatly impacts humans, especially in terms of business and travelling. It is an expected result because this feature is new and has never been created by any systems yet. The output from the user requirement study is illustrated with an empathy map. Fig. 3 shows the empathy map of traveler opinions of the planning process before beginning a trip.

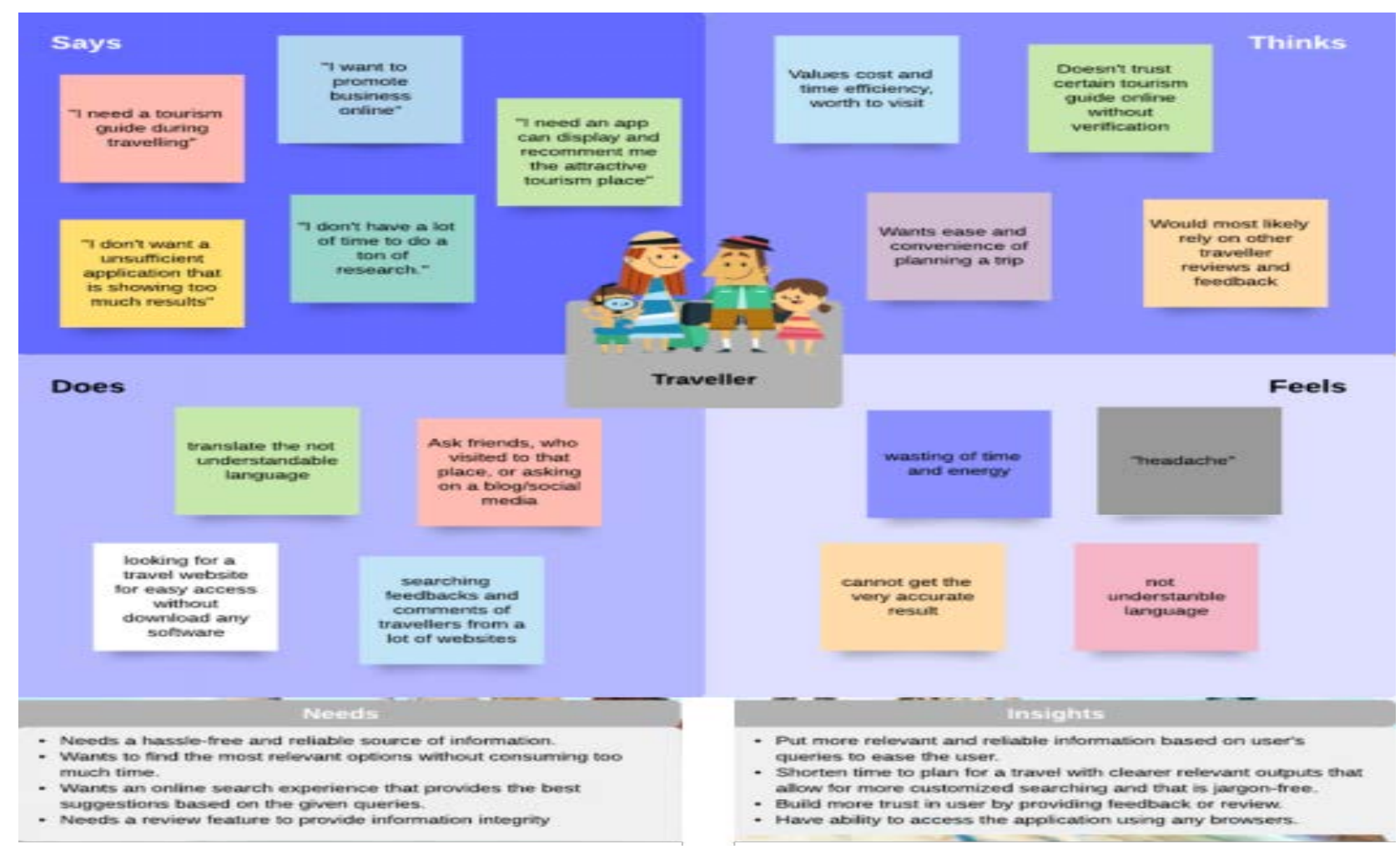

Fig. 3. Empathy Map of Traveler Opinions of the Planning Process before beginning a Trip. 


\section{B. Prototype Development}

Fig. 4 shows some parts of the mobile application prototype, and Fig. 5 shows some parts of the web-based desktop prototype.

A comparison between the designed prototypes with the earlier developed travelling systems, presented in section 2.2, showed similarities between them in providing recommendations to users regarding attractions and tour guides [2, 21-23]. However, this research uniquely took into considerations users' requirements and needs while designing the prototypes. Also, this research designed two prototypes (web-based and mobile) to increase the flexibility of the designed prototypes.

Overall, the UCD approach is chosen because it focuses on the end-users and has been proven to enhance task efficiency and usability of many websites and mobile applications [40, 41]. Travel-related applications should provide a platform to ease the travelling experience for the user. Therefore it's important to adopt a user-centred approach at the earliest stage of travel-related websites and mobile application design and development processes. These could give the end-user the ability to establish and validate important features of travelrelated applications.

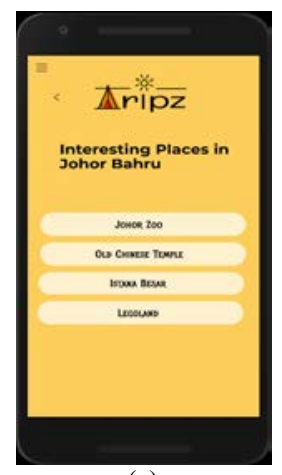

(a)

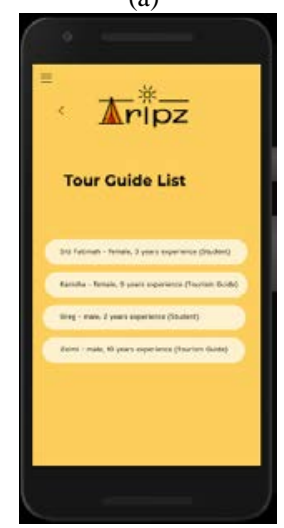

(c)

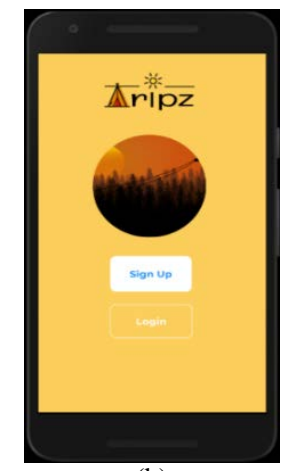

(b)

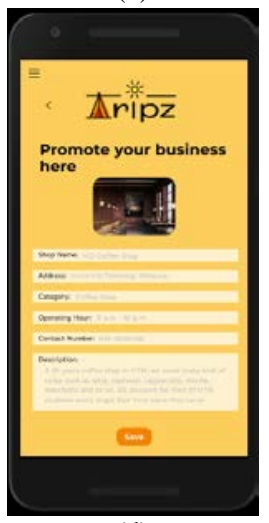

(d)
Fig. 4. Preview of Desktop Prototype: Home Page (a), List of Interesting Places in Johor Bahru (b), Tour Guide List (C) and Vendor Promote Business form Page (d).

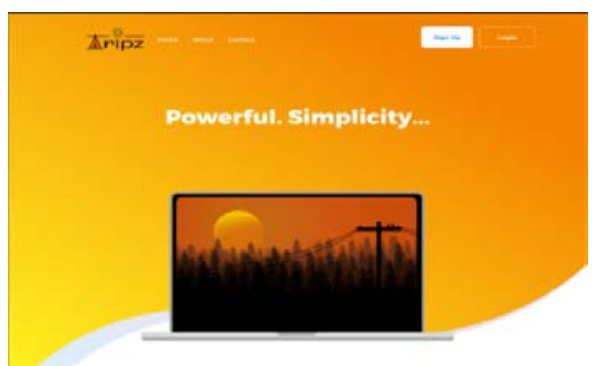

(a)

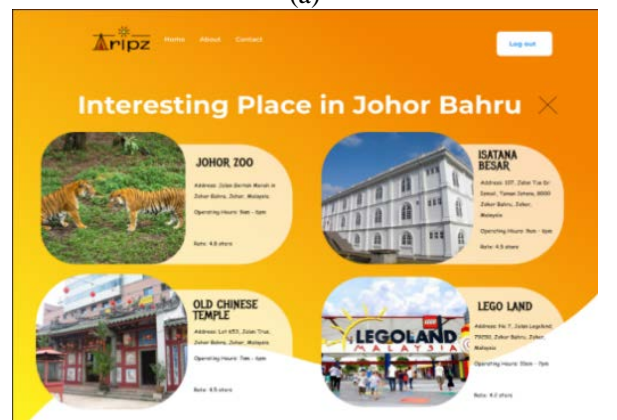

(b)

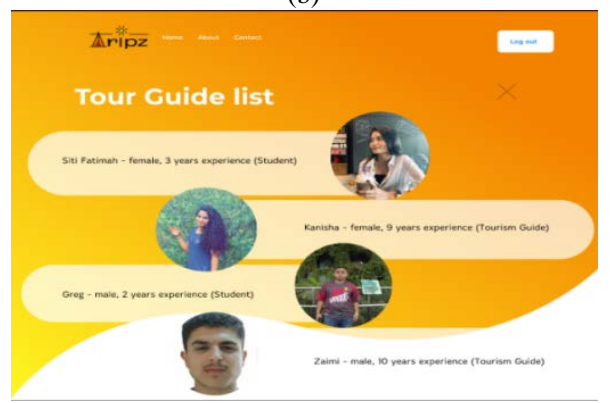

(c)

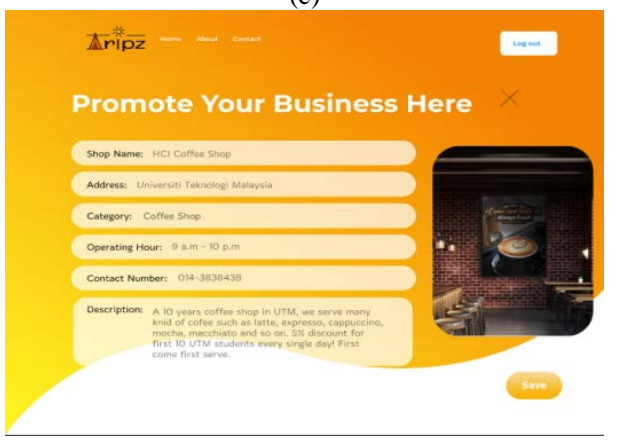

(d)

Fig. 5. Preview of Mobile Prototype: Home Page (a), List of Interesting Places in Johor Bahru (b), Tour Guide List (c) and Vendor Promote Business form Page (d).

\section{Prototype Development}

Fig. 6 shows the task times by each participant for both prototype modules. Meanwhile, Fig. 7 shows the correlation between the task time of Module 1 and Module 2 participant for both prototype modules. Meanwhile, Fig. 7 shows the correlation between the task time of Module 1 and Module 2. 


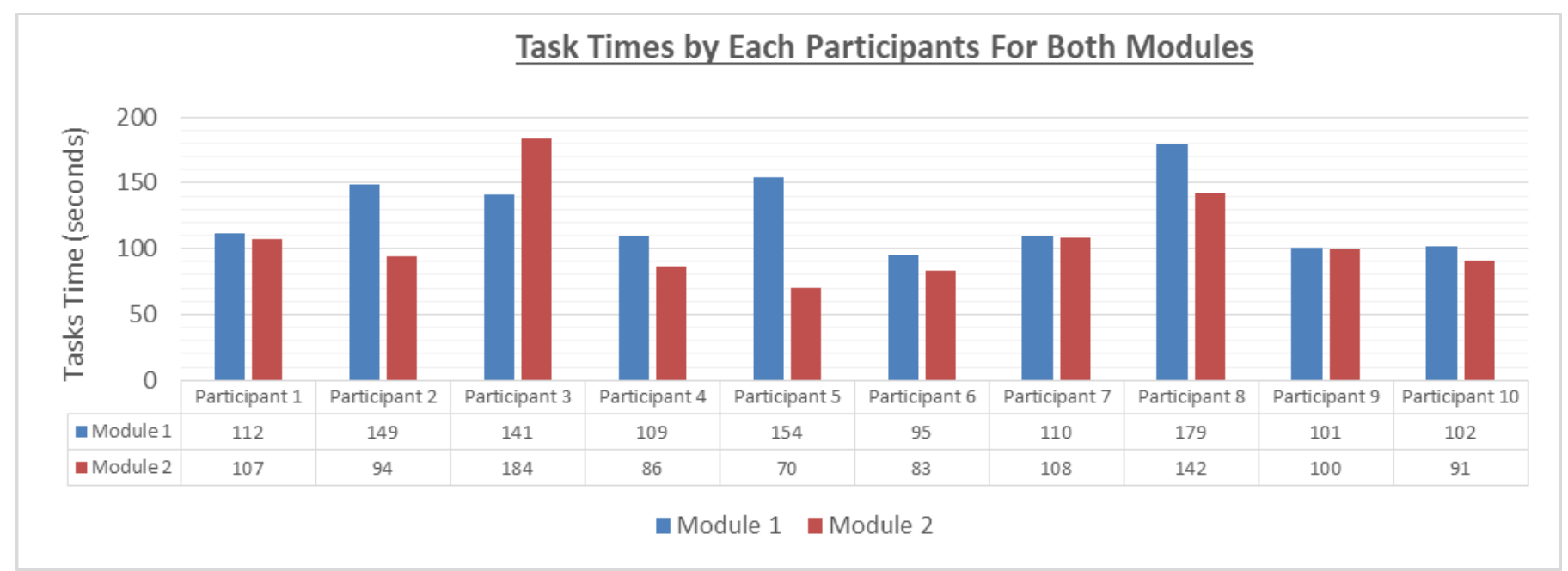

Fig. 6. Task Times by Each Participants for Both Modules.

Fig. 6 shows that participant 3 took the longest time to complete the tasks. To exert a conclusion from this data, the Pearson $r$ correlation test was conducted to determine whether the task times of module 1 and module 2 are correlated to each other. The results of the test are shown in Table I. Since the result is $0.389(-1<0.389<1)$, it means that they are correlated to each other. Additionally, a scatter graph was used to determine whether the correlation between the modules is strong or weak. The graph showed a weak positive correlation. In conclusion, task time for modules 1 and 2 has a weak positive correlation from this correlation result. This indicates that these modules are correlated, but if one variable experiences increments or decrements, the other variable is unlikely to be affected.

In this study, the SUS scores were used as our subjective satisfaction measurement. Table II shows the SUS final scores of each participant for both the prototypes and the mean, standard deviation, and standard error of each module.

A clustered column chart was used to represent the mean result and compare the results graphically, as shown in Fig. 8. As can be seen from Table II, participants 6 and 7 gave low scores. From the recordings, notably, these participants had difficulty dealing with the prototype's button. Comments also were provided from the survey such as "should create a clearer "x" button" and "The flow of the website is not smooth. Also, there is a button that cannot be clicked. It is straightforward, but the button hasn't been fully utilized yet. These two participants' assumptions gave low SUS scores due to the technical issue experienced by the prototypes' buttons. Module 1 (web-based prototype version) has a higher mean than module 2 (mobile application prototype version).

TABLE I. PEARson R CORRELATION TEST RESUlt

\begin{tabular}{|l|l|l|}
\hline & Module 1 & Module 2 \\
\hline Module 1 & 1 & \\
\hline Module 2 & 0.389256 & 1 \\
\hline
\end{tabular}

\section{Correlation Between Task Time Module 1} and Task Time Module 2

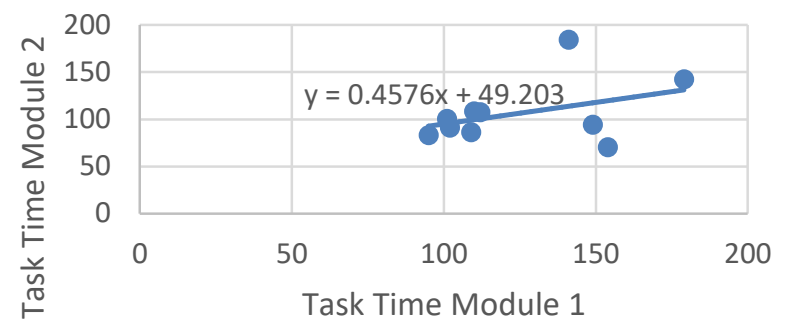

Fig. 7. Correlation between Task Time Module 1 and Task Time Module 2.

TABLE II. THE SUS FINAL SCORES OF EACH PARTICIPANT FOR BOtH PROTOTYPES

\begin{tabular}{|l|l|l|}
\hline & SUS Final Score \\
\hline & Module 1 & Module 2 \\
\hline Participant 1 & 90 & 75 \\
\hline Participant 2 & 82.5 & 92.5 \\
\hline Participant 3 & 92.5 & 82.5 \\
\hline Participant 4 & 80 & 80 \\
\hline Participant 5 & 90 & 92.5 \\
\hline Participant 6 & 52.5 & 55 \\
\hline Participant 7 & 57.5 & 57.5 \\
\hline Participant 8 & 97.5 & 95 \\
\hline Participant 9 & 77.5 & 77.5 \\
\hline Participant 10 & 87.5 & 90 \\
\hline Mean & 80.75 & 79.75 \\
\hline N & 10 & 10 \\
\hline Std dev & 14.8628 & 14.16422 \\
\hline Standard error (SE) & 4.70003 & 4.479118 \\
\hline
\end{tabular}


Earlier research also identified these problems, which evaluated the usability of travel websites, as presented in section 2.1. Specifically, the two issues were identified earlier:

- Not being easy to interact with the website [26, 27];

- Presenting inconvenient, confusing, unclear and vague information [23, 27].

However, while considering the usability problems identified in earlier studies and the suggested usability guidelines recommended by earlier research, this research designed usable prototypes. Only a few issues were identified by the users.

A t-test was used to determine if there is a significant difference between the means of module 1 and module 2 [38, 39]. The t-test value $(t=0.154)$ and the $p$-value $(p=0.879)$, as shown in Table III show no statistically significant difference in SUS scores for prototype 1 and SUS scores for prototype 2. The SUS scores show that the participants do not prefer any of the prototypes more than another one.

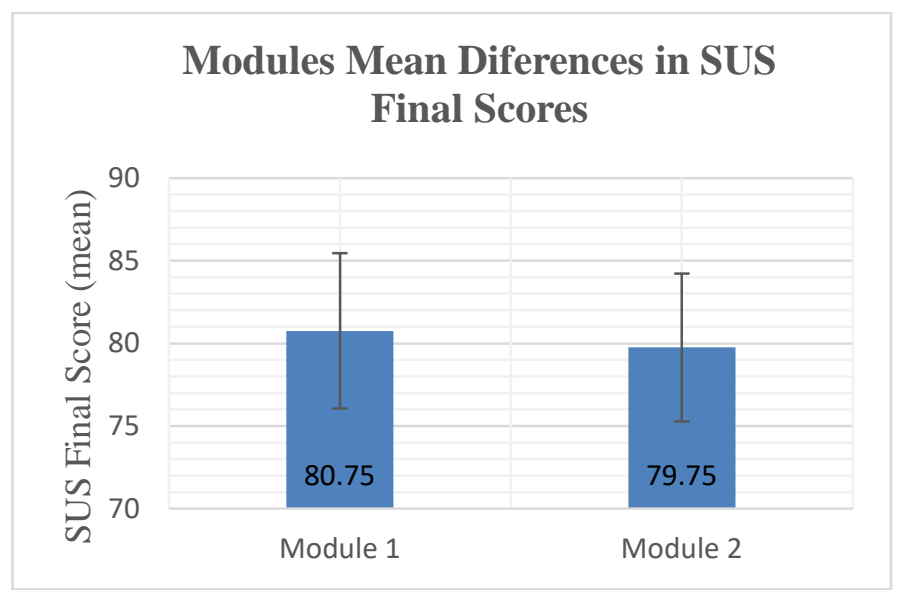

Fig. 8. Clustered Column Chart of Modules Differences in SUS Score.

TABLE III. T-TEST RESULT

\begin{tabular}{|c|c|c|}
\hline \multicolumn{3}{|c|}{ t-Test: Two-Sample Assuming Unequal Variances } \\
\hline & Module 1 & Module 2 \\
\hline Mean & 80.75 & 79.75 \\
\hline Variance & 220.9028 & 200.625 \\
\hline Observations & 10 & 10 \\
\hline Hypothesized Mean Difference & 0 & \\
\hline df & 18 & \\
\hline t Stat & 0.154023 & \\
\hline $\mathrm{P}(\mathrm{T}<=\mathrm{t})$ one-tail & 0.439652 & \\
\hline t Critical one-tail & 1.734064 & \\
\hline $\mathrm{P}(\mathrm{T}<=\mathrm{t})$ two-tail & 0.879305 & \\
\hline t Critical two-tail & 2.100922 & \\
\hline
\end{tabular}

\section{CONCLUSION}

Nowadays, travel applications are the most downloaded applications around the globe. Therefore, it is crucial to have a usable travel application to help the travelers manage their journey and help the travel and tour agency manage their services. This paper aimed to propose an application system design that is easy to use, reliable, and provides the users with the necessary information. Firstly, to gather information on whether users would accept the system, a survey was designed regarding the features and functions proposed for the application. After that, a storyboard was created, a wireframe was designed, and finally, two low-fidelity prototypes were developed using Figma: desktop web-based prototype and mobile prototype. Then, usability testing was employed using the System Usability Scale (SUS) questionnaire. The results showed that users have no preference towards any of the prototypes. The next step is to develop the designed prototypes taking into consideration the usability problems which were identified.

\section{ACKNOWLEDGEMENT}

This work was supported by the Ministry of Higher Education (MOHE) Malaysia. We would like to thank MOHE, Universiti Teknologi Malaysia and UTM VicubeLab research group for this support.

\section{REFERENCES}

[1] F. Mamaghani, "Impact of E-commerce on Travel and Tourism: An Historical Analysis". International Journal of Management, vol. 26, no. 3, pp. 365-375, 2009.

[2] A. Smirnov, et al., "Mobile Application for Guiding Tourist Activities: Tourist Assistant - TAIS", In the Proceedings of the 16th Conference of Open Innovations Association FRUCT, Oulu, Finland, IEEE, pp. 94100, 2014.

[3] Palos-Sanchez P., et al., "Do Tourism Applications' Quality and User Experience Influence Its Acceptance By Tourists?”, Review of Managerial Science, vol. 15, pp. 1205-1241, 2021.

[4] S. Lin, "The Critical Success Factors for A Travel Application Service Provider Evaluation and Selection by Travel Intermediaries", Tourism Management, vol. 56, pp. 126-141, 2016. Retrieved from: 10.1016/j.tourman.2016.03.028.

[5] H. Batista, "7 Reasons Why Search Engines Don't Return Relevant Results $100 \%$ of the Time", Moz, 2007. [Online]. Retrieved from: https://moz.com/blog/7-reasons-why-search-engines-dont-returnrelevant-results-100-of-the-time.

[6] D. Lewandowski, "Problems with The Use of Web Search Engines to Find Results in Foreign Languages", Online Information Review, vol. 32, no. 5, pp. 668-672, 2008. Retrieved from: https://doi.org/10.1108/14684520810914034.

[7] A. Bainbridge, "Hotel Booking Process, Design \& Usability Report", Technical Report, Travel UCD, Consultants in Travel and Hospitality Website Design, February 2003. Retrieved from: http://www.travelucd.com.

[8] D. Ukpabi and H. Karjaluoto, "Consumers' Acceptance of Information and Communications Technology in Tourism: A Review", Telematics and Informatics, vol. 34, no. 5, pp. 618-644, 2017. Retrieved from: https://www.sciencedirect.com/science/article/abs/pii/S07365853163033 67.

[9] E. Novoseltseva, "User-Centered Design: An Introduction - Usability Geek", Usability Geek, 2020. [Online]. Retrieved from: https://usabilitygeek.com/user-centered-design-introduction/. 
[10] The Interaction Design Foundation. 2021. What is User Centered Design? Retrieved from:https://www.interaction-design.org/literature/ topics/user-centered-design.

[11] W.A.A.W. Daud, et al., "The Usability of I-Suyyah: A Mobile Tourism Application for Arab Tourists in Malaysia”, Enlightening Tourism. A Pathmaking Journal, vol. 11, no. 1, pp. 263-286, 2021.

[12] Sunny Sun, et al., "An Updated Comprehensive Review of Website Evaluation Studies in Hospitality and Tourism”, International Journal of Contemporary Hospitality Management, vol. 29, no. 1, pp. 355-373, 2017.

[13] Sánchez-Torres J. A., et al. "Adoption of Tourist Mobile Applications Motivating Factors for their Use, an Exploratory Study in Spanish Millennials", Journal of Telecommunications and the Digital Economy, vol. 9, no. 1, pp. 1-18, 2021.

[14] Anaya-Aguilar R., et al., "Usability Analysis of Andalusian Spas' Websites”, Sustainability, vol. 13, no. 4, pp. 1-14, 2021.

[15] J. Nielsen, "Usability 101: Introduction To Usability," Jakob Nielsen's Alertbox. Retrieved from: https://www.nngroup.com/articles/usability101-introduction-to-usability/.

[16] A. Smith, "Usability First - Why Usability Design Matters to UI/UX Designers", Medium, 2017. Retrieved from: https://uxplanet.org/ usability-first-why-usability-design-matters-to-ui-ux-designers9dfb5580116a.

[17] S. Lin, et al., "A TAM Framework to Evaluate the Effect of Smartphone Application on Tourism Information Search Behavior of Foreign Independent Travelers", Sustainability, vol. 12, no. 22, p. 9366, 2020.

[18] J. Fang, et al. "Design and Performance Attributes Driving Mobile Travel Application Engagement", International Journal of Information Management, vol. 37, no. 4, pp. 269-283, 2017. Retrieved from: 10.1016/j.ijinfomgt.2017.03.003.

[19] M. van Setten, et al., "Context-Aware Recommendations in the Mobile Tourist Application COMPASS”, Adaptive Hypermedia and Adaptive Web-Based Systems, In the Proceedings of Third International Conference, AH 2004, Eindhoven, The Netherlands, August 23-26, 2004.

[20] R. Anacletoa, et al., "Mobile Application to Provide Personalised Sightseeing Tours", Journal of Network and Computer Applications, vol. 00, pp. 1-10, 2013.

[21] R. Kramer, et al., "Development and Evaluation of a Context-Driven, Mobile Tourist Guide", International Journal of Pervasive Computing and Communications, vol. 3, no. 4, pp. 378-, 2005.

[22] K. Cheverst, et al., "Developing a Context-aware Electronic Tourist Guide: Some Issues and Experiences”, Distributed Multimedia Research Group, Lancaster University, UK, 2002.

[23] A. Ismail, et al., "iTourism Travel Buddy Mobile Application”, In the Proceedings of 10th International Conference on Next Generation Mobile Applications, Security and Technologies, pp. 82-87, Cardiff, The UK, 24-26 August 2016. Retrieved from: https://oi.org/ 10.1109/NGMAST.2016.22.

[24] N. L. Hashim, and A. J. Isse, "Usability Evaluation Metrics of Tourism Mobile Applications", Journal of Software Engineering and Applications, vol. 12, pp. 267-277, 2019. Retrieved from: http://www.scirp.org/journal/jsea.

[25] S. Böhm, "Do You Know Your User Group? Why It Is Essential to Put Your User-Requirements Analysis On A Broad Database", Universal
Access in the Information Society, 2021. Retrieved from: https:/link.springer.com/article/10.1007/s10209-021-00805-3.

[26] D. S. Carstens and P. Patterson, "Usability Study of Travel Websites", Journal of Usability Studies, vol. 1, no.1, pp. 47-61, November 2005.

[27] A. Limayem, et al., "Sophistication of Online Tourism Websites in Hong Kong: An Exploratory Study”. In the Proceedings of the Americas Conference on Information Systems, 4-6 August, Tampa, USA, 2003.

[28] S. Karanasios, et al., "A Classification of Mobile Tourism Applications”, Carmine, Chapter 11, Global Hospitality and Tourism Management Technologies, IGI Global, 2012.

[29] "Why Storyboarding for Websites Is Important", Wearewhitehat.com, 2013. Retrieved from: https://wearewhitehat.com/blog/2013/whystoryboarding-for-websites-is-important/.

[30] J. Nielsen, "Authentic Behavior in User Testing", Nielsen Norman Group, 2005. Retrieved from: https:/www.nngroup.com/articles/ authentic-behavior-in-user-testing/.

[31] K. Whitenton, "Tools for Unmoderated Usability Testing", Nielsen Norman Group, 2019. Retrieved from: https://www.nngroup.com/ articles/unmoderated-user-testing-tools.

[32] P. Laubheimer, "Beyond the NPS: Measuring Perceived Usability with the SUS, NASA-TLX, and the Single Ease Question After Tasks and Usability Tests", Nielsen Norman Group, 2018. Retrieved from: https://www.nngroup.com/articles/measuring-perceived-usability/].

[33] N. Thomas, "How to Use the System Usability Scale (SUS) To Evaluate the Usability of Your Website - Usability Geek", Usability Geek. Retrieved from: https://usabilitygeek.com/how-to-use-the-systemusability-scale-sus-to-evaluate-the-usability-of-your-website/.

[34] "Low-Fidelity Prototype Testing", Maze.design. [Online]. Retrieved from: https://maze.design/use-case/low-fidelity-prototype-testing.

[35] J. Nielsen, "Why You Only Need to Test with 5 Users", Nielsen Norman Group, 2000. [Online]. Retrieved from: https://www.nngroup.com/ articles/why-you-only-need-to-test-with-5-users/.

[36] M. Tongco, "Purposive Sampling as a Tool for Informant Selection", Ethnobotany Research and Applications, vol. 5, p. 147, 2007. Retrieved from: 10.17348/era.5.0.147-158.

[37] "Purposive Sampling 101, SurveyGizmo Blog", Alchemer, 2018. Retrieved from: htt1s://www.alchemer.com/resources/blog/purposivesampling-101.

[38] O. Packages et al., "FAQ: What are the differences between one-tailed and two-tailed tests?", Stats.idre.ucla.edu, 2021. Retrieved from: https://stats.idre.ucla.edu/other/mult-pkg/faq/general/faq-what-are-thedifferences-between-one-tailed-and-two-tailed-tests.

[39] P. M.K. Trochim, "Research Methods Knowledge Base: Inferential Statistics", Conjointly.com, 2020. Retrieved from: https://conjointly. $\mathrm{com} / \mathrm{kb} /$ inferential-statistics/.

[40] Haines, E.R., Dopp, A., Lyon, A.R. et al. Harmonizing evidence-based practice, implementation context, and implementation strategies with user-centered design: a case example in young adult cancer care. Implement Sci Commun 2, 45 (2021). Retrieved from: https://doi.org/10.1186/s43058-021-00147-4

[41] Constance M. Johnson, Todd R. Johnson, Jiajie Zhang, A user-centered framework for redesigning health care interfaces, Journal of Biomedical Informatics, Volume 38, Issue 1, 2005, Pages 75-87. Retrieved from: https://doi.org/10.1016/j.jbi.2004.11.005. 